\title{
Avaliação da aprendizagem: percepções docentes em sessões tutoriais de um curso de medicina na Amazônia
}

\author{
Learning assessment: teaching perceptions in tutorial \\ sessions of a medicine course in the Amazon
}

Marília de Fátima Silva Pinheiro', Milena Coelho Fernandes Caldato', Jackson Cordeiro Lima', Fabíola de Carvalho Chaves de Siqueira Mendes ${ }^{1}$

'Centro Universitário do Estado do Pará, Belém (PA), Brasil.

\section{RESUMO}

O método PBL (Problem Based Learning - Aprendizagem baseada em problemas) é uma dinâmica curricular que tenta responder às demandas contemporâneas para o ensino da Medicina. Essa metodologia ocorre no formato de sessão tutorial e utiliza como avaliação, aquela de natureza formativa. Objetivo: com o objetivo de analisar o processo de como essa avaliação acontece nas sessões tutoriais de um curso de Medicina em uma instituição de ensino superior privada, foi realizado um estudo transversal com docentes do Curso. Métodos: a pesquisa utilizou questionários com perguntas fechadas. Resultados: $48 \%$ dos docentes eram do sexo feminino; com relação à titulação acadêmica, haviam $59 \%$ mestres, $26 \%$ doutores e $15 \%$ especialistas. Observou-se que, $77,8 \%$ dos tutores sempre utilizaram a planilha de avaliação, $73 \%$ concordaram com as pontuações dos critérios dessa planilha, mas solicitaram rever determinados pontos. Docentes citaram como característica mais importante para ser um bom tutor ter o conhecimento técnico e a menos importante, ter abertura às críticas. Conclusão: com base nos resultados, sugere-se que, são necessárias mudanças na descrição e nas pontuações dos critérios dessa planilha de avaliação e que as dinâmicas de grupo devam ser revistas regularmente pelos tutores, além de acesso a programas de treinamento e de desenvolvimento profissional contínuo para estes professores.

PALAVRAS-CHAVE: Avaliação. Tutoria. Aprendizagem baseada em problemas.

Recebido: Jun. 11, 2017 Aceito: Nov. 20, 2017

\section{COMO CITAR ESTE ARTIGO}

Pinheiro MFS, Caldato MCF, Lima JC, Mendes FCCS. Avaliação da aprendizagem: percepções docentes em sessões tutoriais de um curso de medicina na Amazo um curso de medicina na Amazôni Interdisciplinary Journal of Health Education. 2017 Jan-Jul;2(1):25-32 https://doi.org/10.4322/ijhe.2016.025

\section{CORRESPONDÊNCIA:}

Marília de Fátima Silva Pinheiro

Centro Universitário do Estado do Pará Av. Almirante Barroso, 3775 , CEP 66613-903, Souza Belém (PA), Brasil

marilia.pinheiro@globo.com

\section{FONTE DE FINANCIAMENTO}

Nenhuma.

\section{CONFLITO DE INTERESSE}

Os autores declararam não

haver conflitos de interesse.

\section{ABSTRACT}

The PBL (Problem Based Learning) method is a dynamic curriculum that attempts to answer the contemporary demands for medical education. This methodology is in the tutorial session format and uses as assessment, formative nature. Objective: in order to analyze the process of how this happens in the tutorial sessions of the Medical School, a cross-sectional was conducted with teachers of the course. Methods: the research used questionnaires with closed questions. Results: among the teachers, $48 \%$ were female; with respect to academic degrees, $59 \%$ had masters, $26 \%$ doctors' science and $15 \%$ expert. Observed that $77.8 \%$ of the tutors always used the evaluation sheet, $73 \%$ agreed with the scores of the criteria that worksheet, but asked to review certain point. Teachers cited as the most important feature to be a good tutor to have technical knowledge and the least open to criticism. Conclusion: it is suggested that changes in the description and the criteria scores this evaluation sheet are necessary and that the group dynamics should be reviewed regularly by tutors, and access to training and ongoing professional development programs for these teachers.

KEYWORDS: Evaluation. Mentoring. Problem Based Learning. 


\section{Introdução}

No Brasil as Diretrizes Curriculares para os cursos de Medicina ${ }^{1}$ atualizadas em 2014, propuseram não apenas a revisão dos conteúdos curriculares, mas também a busca de novas metodologias de ensino que propiciassem um novo pensar teórico-metodológico de formação acadêmica.

O método da Aprendizagem Baseada em Problemas (Problem Based Learning - PBL) constitui-senuma dinâmica curricular que responde a essas demandas contemporâneas ${ }^{2}$. O referido método, ao centralizar o processo de aprendizagem no auto estudo pelo aluno, coloca o professor na condição de facilitador desse processo, pondo fim às práticas habituais de ensino, nas quais o professor (sujeito ativo) é considerado o exclusivo detentor dos saberes e o aluno simples receptor (sujeito passivo) deles ${ }^{3}$.

Nesse contexto, a avaliação constitui-se como etapa relevante, permitindo ao docente apreciar o processo de aprendizagem do aluno na obtenção de subsídios para as mudanças que forem necessárias. Em todo processo didático-pedagógico provavelmente a avaliação constitui a etapa de maior relevância e dificuldade na obtenção de informações sobre o aprendizado do aluno. Além disso, a forma e o conteúdo em como avaliar são importantes, por constituírem poderoso determinante de como os alunos estudam e aprendem ${ }^{4}$.

Avaliar não mobiliza meramente aspectos cognitivos. Em grande parte, aspectos subjetivos estão presentes e sabe-se que os conhecimentos dos tutores/professores sobre a avaliação estão alicerçados em uma visão tradicional que dá ênfase aos instrumentos de caráter quantitativos (geralmente a prova ${ }^{5,6}$.

À medida que se utiliza a avaliação formativa, a aprendizagem ganha contornos mais bem definidos, pois o aluno é avaliado sob outra ótica - a observação Porém os tutores/professores vivem o sentimento de dúvidas quanto ao estar fazendo o processo de maneira adequada ou não. Nesse aspecto ocorrem divergências de ponto de vista, no que considerar normal, uma vez que, sujeitos têm visões de mundo, vida, profissional distintos entre si, o que torna a avaliação um campo complexo ${ }^{7}$.

Surgem várias interrogações do ponto de vista dos tutores/professores: o feedback realizado está sendo suficiente? Como saber se as intervenções produzirão modificações na aprendizagem dos alunos?

Além de terem que superar a prática de avaliação do ensino tradicional de caráter somatório, prática essa de maior experiência desses profissionais, faz-se necessária uma maior segurança desses profissionais no momento de avaliar, pois nem sempre o estudo e/ou experiência prévia são sinônimos de avaliação justa.

Esta pesquisa utilizou como contexto o curso de Medicina de uma instituição privada de Belém-PA, que em 2007 iniciou a primeira turma com metodologia PBL. Até o oitavo período, os alunos discutem situações-problemas em duas sessões tutoriais semanais. Após a discussão tanto na abertura como no fechamento dessas situações, é realizada a avaliação formativa pelos discentes e docentes, estes realizam neste momento o feed-back aos alunos. A avaliação é baseada em critérios pré-estabelecidos pela Instituição (planilha de avaliação na abertura e fechamento do problema) com conversão para conceitos e pontuação.

Portanto, foi objetivo deste trabalho analisar o processo de avaliação formativa das sessões tutoriais no curso de Medicina de uma instituição privada de Belém-PA, além de descrever as dificuldades na condução da sessão tutorial, identificadas pelo docente; descrever se existem conceitos preconcebidos de aluno bom e fraco; correlacionar titulação docente com avaliação de aluno de diferentes níveis de desempenho acadêmico e correlacionar titulação e tempo de experiência em metodologias ativas com o uso da planilha de avaliação. 


\section{Metodologia}

Esta pesquisa foi incluída na Plataforma Brasil e aprovada pelo Comitê de Ética em Pesquisa em Seres Humanos do Centro Universitário do Estado do Pará - CESUPA (parecer número 233.998) e seguiu todos os preceitos éticos de pesquisas em seres humanos. Todos os que aceitaram participar, assinaram o Termo de Conhecimento Livre e Esclarecido - TCLE.

O estudo transversal quantitativo realizado utilizou para a pesquisa de campo a aplicação de questionário com perguntas fechadas. Por se tratar de um questionário inédito e não validado, foi aplicado um piloto com $20 \%$ da casuística total de tutores (oito professores). Após a aplicação dos questionários piloto, as respostas foram analisadas e ajustes realizados para melhor compreensão com posterior aplicação à casuística total.

Ao final da aplicação dos questionários, os dados foram compilados em planilha de Excel e submetidos à análise estatística. A análise de cada questão dos questionários foi realizada de forma descritiva, fazendo o uso das frequências absolutas das respostas (primeira a décima questão).

Nas questões em que foram solicitadas para que o participante ordenasse as opções de forma a responder a indagação, foi utilizada a moda ( $11^{\mathrm{a}}$ a $13^{\mathrm{a}}$ questões). Tabelas de contingências foram construídas para analisar a correlação entre as respostas.

\section{Resultados e discussão}

A pesquisa conseguiu atingir a totalidade dos tutores/professores que exerciam suas atividades do primeiro ao oitavo períodos no segundo semestre de 2013, com ampla aceitação por parte dos professores, não havendo recusas de participação. O questionário, portanto, foi aplicado a 27 tutores (48,1\% do sexo feminino e $51,9 \%$ do sexo masculino), uma vez que oito professores exerciam o papel de tutor em mais de uma turma.

De acordo com Freire ${ }^{8}$, o educador precisa entender que ensinar não é apenas o simples fato de transferir conhecimento para o aluno, e sim criar condições para que este produza ou construa seu conhecimento. O PBL é um método que incentiva esta construção do conhecimento, porém tanto os professores quanto os alunos que o praticam apresentam dúvidas com relação a sua correta aplicabilidade. Tal fato pode justificar o total interesse dos docentes em participar desta pesquisa.

Do total de professores analisados, 14,8\% eram especialistas, 59,3\% mestres e $25,9 \%$ doutores. $11,1 \%$ possui até dois anos de magistério no ensino superior, $22,2 \%$ entre 2 e 5 anos e $66,7 \%$ com 6 anos ou mais. 25,9\% possuem até dois anos de experiência com metodologias ativas, $44,43 \%$ entre dois e cinco anos e $29,63 \%$ com seis anos ou mais.

No que se refere a análise da primeira questão: "Sempre utilizo a planilha com os critérios para avaliação formativa em tutorias", evidenciou que 77,8\% dos tutores sempre a utilizaram e 14,8\% frequentemente a utilizaram; contra $7,4 \%$ que não ou quase nunca a utilizaram (Figura 1).

Apesar da maioria dos tutores $(77,8 \%)$ ter afirmado que usava a planilha com os critérios para avaliação formativa, chama atenção ainda, que 7,4\% dos docentes não ou quase nunca utilizaram a planilha de avaliação, levantando o questionamento de quais parâmetros tais professores estariam utilizando para avaliar seus alunos. Segundo Fernandes ${ }^{9}$, mudanças e melhorias na avaliação formativa implicam que o seu significado seja claro para os professores.

Com relação à questão de número cinco: "O aluno que foi muito bem nos primeiros problemas poderá até eventualmente cair o seu rendimento, mas não é justo diminuir suas notas", mostrou que $77,8 \%$ dos docentes discordaram totalmente; 


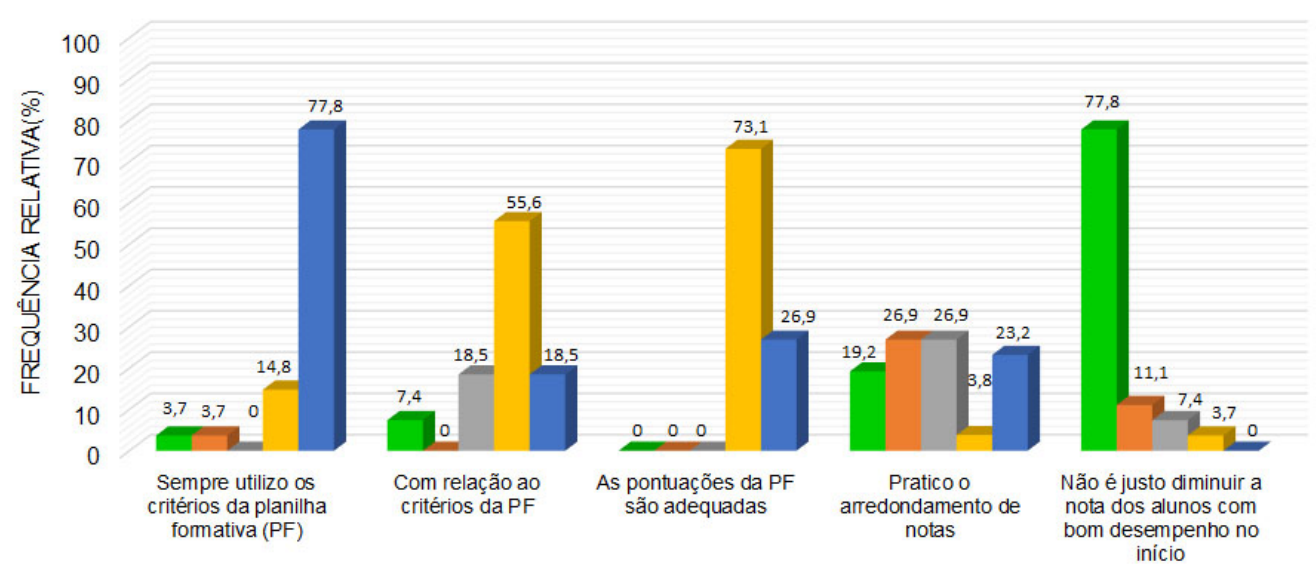

- Não concordo totalmente $\approx$ Não concordo parcialmente $=$ Indiferente $\backsim$ Concordo parcialmente $\approx$ Concordo totalmente

Figura 1. Frequência relativa das repostas (em percentual) dos docentes às perguntas de 1 a 5 do questionário sobre como é realizada a avaliação dos alunos durante a Aprendizagem Baseada em Problemas.

$11,1 \%$ discordaram em parte; $7,4 \%$ marcaram às vezes, pois dependeria do aluno e 3,7\% concordaram em partes (Figura 1).

Com relação à essa questão, é importante notar que a maioria dos tutores $(77,8 \%)$ diminuiria a nota deste aluno, avaliando como tinha sido seu desempenho naquele dia, não importando se ele era considerado de alto desempenho, sugerindo que não existiriam conceitos preconcebidos de que alunos de bom rendimento sempre seriam alunos de notas altas.

Coerentemente, a sexta assertiva (i.e "O aluno que tenha sido fraco nos primeiros problemas dificilmente cresce e assim mantenho sua nota praticamente igual"), revelou que $74,1 \%$ dos tutores discordaram totalmente e $11,1 \%$ discordaram em partes; $11,1 \%$ disseram que dependeria do aluno e 3,7 concordaram totalmente (Figura 2).

Desse modo, assim como na assertiva que se referia ao aluno de baixo rendimento que no decorrer das tutorias vai melhorando seu rendimento, a maioria dos professores $(74,1 \%)$ aumentaria a sua nota de acordo com seu desempenho diário, corroborando para o fato de que os tutores não colocariam rótulos nos alunos, porém chama atenção que seria mais fácil para eles $(77,8 \%)$ reduzirem a nota de um aluno de alto desempenho do que aumentar a nota de outro de baixo rendimento $(74,1 \%)$. Veiga ${ }^{10}$ cita como princípio para ajudar a realizar a avaliação formativa, a necessidade de o professor abrir mão do uso autoritário da avaliação, afinal ela não serve para castigar o aluno e sim para saber se ele aprendeu ou não o conteúdo e assim, pensar em estratégias para reverter tal situação.

Em relação à sétima afirmativa: "Percebo que às vezes, com extremo cansaço diminuo o meu nível de atenção e eventualmente isso chega a prejudicar a minha avaliação individual do aluno", evidenciou que $55,6 \%$ dos tutores já tiveram momentos de distração, mas acreditaram não ter afetado sua avaliação; em $25,9 \%$ dos professores já ocorreu algumas vezes e para 18,5\% dos docentes, tal fato nunca ocorreu (Figura 2).

Com esse resultado, nota-se que, apesar de o PBL ser centrado no aluno, o método necessita intensa participação do tutor, que passa a atuar como orientador, mentor e co-aprendiz, portanto exigindo muito mais atenção dele. Oficinas sobre técnicas e sobre pedagogia podem ser capazes de capacitar os docentes, mas são necessários programas de desenvolvimento docente para dar sustento aos currículos em formato PBL ${ }^{11}$.

À cerca da solicitação encontrada na $11^{a}$ questão: "Enumere na ordem da mais importante para a menos importante as características que julga serem importantes para um tutor fazer uma boa avaliação (i.e escuta ativa; abertura às críticas; 


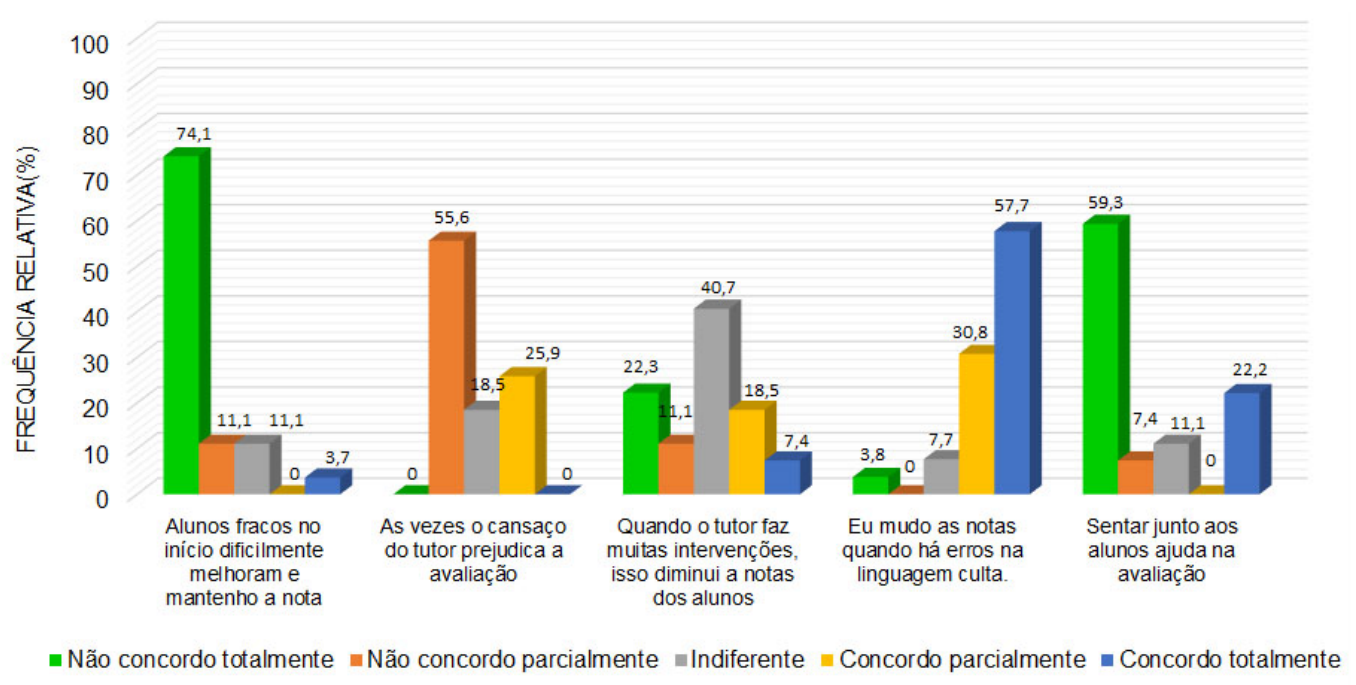

Figura 2. Frequência relativa das repostas (em percentual) dos docentes às perguntas de 6 a 10 do questionário sobre como é realizada a avaliação dos alunos durante a Aprendizagem Baseada em Problemas.

conhecimento técnico; auxílio ao foco; fornecimento de feedback"), mostrou que a mais importante foi ter conhecimento técnico, seguida de fornecer escuta ativa e a menos importante foi estar aberto às críticas, o que também foi achado na prática, pois os próprios professores estavam exercendo no seu dia a dia mais a escuta ativa e tendo conhecimento técnico do que abertos às críticas (Tabela 1).

Sobre o comando da $12^{a}$ questão: "Baseado nas características para um tutor enumere na forma da mais frequente para a menos frequente as características que você exercita nas tutorias: 1 . Escuta ativa. 2. Abertura às críticas. 3. Conhecimento técnico. 4. Auxílio ao foco. 5. Fornecimento de feedback.", mostrou que a mais frequente foi a alternativa 1, a segunda mais frequente foi a alternativa 3 e a menos frequente foi a alternativa 2 (Tabela 1 ).

Nesse caso, é importante a reflexão de que ouvir é uma das habilidades de comunicação mais importante para um tutor, mas esta escuta deve ser ativa, o tutor tem que prestar atenção no que está sendo dito, respeitar seus próprios pensamentos e sentimentos, evitando interromper o aluno e esperar o momento correto para fazer suas colocações ${ }^{12}$.

Sobre o $13^{\text {a }}$ enunciado: "De acordo com sua dificuldade, coloque na ordem da mais difícil para a mais fácil situação" (i.e fazer avaliação formativa do aluno de desempenho regular em turmas muito boas; fazer avaliação formativa do aluno de desempenho regular em turmas muito fracas; motivar uma turma composta pela maioria de alunos desmotivados; estimular um aluno tímido a falar; estimular a capacidade de liderança de um coordenador não participativo; motivar a participação de um relator que não se pronuncia), a análise evidenciou que a mais difícil foi motivar uma turma com a maioria de desmotivados, seguida de estimular o aluno tímido e a mais fácil foi a avaliação de aluno regular em turma de alto rendimento (Tabela 1).

Estes resultados se contrapõem a outros da literatura em que é apresentado como problemas mais comuns do PBL, na visão dos tutores, os alunos muito quietos que deixam a sessão tutorial mais difícil, pois sem contribuir, acabam sobrecarregando a participação dos colegas ${ }^{13}$.

Ao se correlacionar a titulação apresentada pelo docente com a afirmativa: "O aluno que foi muito bem nos primeiros problemas poderá até eventualmente cair o seu rendimento, mas não é justo diminuir suas notas", foi observado que a maioria dos professores (21 de 27) discordou totalmente, independente da sua titulação. Dentre os seis docentes restantes, três discordaram em partes, sendo dois mestres e 
Tabela 1. Descrição dos itens marcados por cada docente para efeito de resposta às perguntas de 11 a 14 do questionário sobre sua percepção ao exercício da função de tutor durante o método de Aprendizagem Baseada em Problemas. Abaixo destaca-se a moda, ou seja, o item que mais se fez presente como resposta dos docentes.

\begin{tabular}{|c|c|c|c|c|c|c|c|c|}
\hline \multirow{3}{*}{ 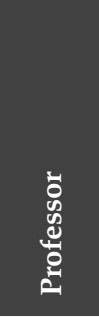 } & \multicolumn{2}{|c|}{ Questão XI } & \multicolumn{2}{|c|}{ Questão XII } & \multirow{2}{*}{\multicolumn{2}{|c|}{$\begin{array}{l}\text { Questão XIII } \\
\begin{array}{c}\text { Situações de } \\
\text { condução de } \\
\text { tutoria }\end{array}\end{array}$}} & \multirow{2}{*}{\multicolumn{2}{|c|}{$\begin{array}{c}\text { Questão XIV } \\
\text { Prática de } \\
\text { preferência } \\
\text { durante a tutoria }\end{array}$}} \\
\hline & \multicolumn{2}{|c|}{$\begin{array}{c}\text { Características } \\
\text { importantes para o tutor } \\
\text { fazer uma boa avaliação }\end{array}$} & \multicolumn{2}{|c|}{$\begin{array}{l}\text { Características } \\
\text { exercitadas em tutorias }\end{array}$} & & & & \\
\hline & $\begin{array}{c}\text { Mais } \\
\text { Importante }\end{array}$ & $\begin{array}{c}\text { Menos } \\
\text { Importante }\end{array}$ & $\begin{array}{c}\text { Mais } \\
\text { Frequente }\end{array}$ & $\begin{array}{c}\text { Menos } \\
\text { Frequente }\end{array}$ & $\begin{array}{l}\text { Mais } \\
\text { Difícil }\end{array}$ & $\begin{array}{l}\text { Mais } \\
\text { Fácil }\end{array}$ & $\begin{array}{l}\text { Mais } \\
\text { Gosta }\end{array}$ & $\begin{array}{c}\text { Menos } \\
\text { Gosta }\end{array}$ \\
\hline p01 & 5 & 2 & 5 & 4 & 4 & 3 & 2 & 3 \\
\hline p02 & 3 & 4 & 3 & 2 & 4 & 2 & 2 & 3 \\
\hline p03 & 1 & 4 & 1 & 3 & 3 & 2 & 2 & 4 \\
\hline p04 & 1 & 4 & 1 & 4 & 3 & 5 & 1 & 3 \\
\hline p05 & 3 & 2 & 1 & 2 & 1 & 3 & 2 & 4 \\
\hline p06 & 1 & 4 & 1 & 4 & 2 & 4 & 5 & 3 \\
\hline p07 & 3 & 2 & 3 & 2 & 3 & 1 & 1 & 4 \\
\hline p08 & 5 & 2 & 1 & 5 & 3 & 2 & 5 & 4 \\
\hline p09 & 1 & 2 & 1 & 2 & 2 & 1 & 5 & 3 \\
\hline p10 & 3 & 5 & 3 & 5 & 1 & 5 & 5 & 4 \\
\hline p11 & & & & & & & & \\
\hline p12 & 1 & 3 & 1 & 3 & 4 & 1 & 5 & 4 \\
\hline p13 & 3 & 2 & 3 & 2 & 4 & 6 & 2 & 3 \\
\hline p14 & 3 & 2 & 1 & 2 & 4 & 2 & 5 & 4 \\
\hline p15 & 1 & 5 & 1 & 5 & 3 & 1 & 1 & 4 \\
\hline $\mathrm{p} 16$ & 3 & 2 & 1 & 2 & 3 & 1 & 2 & 3 \\
\hline p17 & 5 & 3 & 5 & 3 & 4 & 2 & 1 & 4 \\
\hline $\mathrm{p} 18$ & 1 & 2 & 1 & 2 & 4 & 1 & 1 & 4 \\
\hline p19 & 3 & 4 & 1 & 2 & 2 & 5 & 1 & 3 \\
\hline p20 & 1 & 2 & 1 & 3 & 3 & 1 & 5 & 3 \\
\hline p21 & 3 & 2 & 3 & 5 & 3 & 1 & 1 & 4 \\
\hline p22 & 2 & 5 & 2 & 4 & 1 & 6 & 3 & 1 \\
\hline p23 & 3 & 2 & 1 & 5 & 4 & 6 & 2 & 3 \\
\hline p24 & 3 & 2 & 1 & 2 & 3 & 4 & 1 & 3 \\
\hline p25 & 2 & 3 & 2 & 3 & 3 & 1 & 2 & 4 \\
\hline p26 & 5 & 1 & 1 & 5 & 3 & 1 & 2 & 4 \\
\hline p27 & 1 & 2 & 1 & 2 & & & & \\
\hline Moda & 3 & 2 & 1 & 2 & 3 & 1 & 2 & 4 \\
\hline
\end{tabular}

um especialista; dois acreditaram que dependeria do aluno, sendo um mestre e um doutor e um mestre concordou em partes.

Nessa correlação, ficou evidente que a maioria dos tutores não rotula o aluno como de alto rendimento $(78 \%)$, independente da sua titulação. Entretanto, um professor com o título de mestre ainda concordou em partes com o fato de rotular o aluno como bom e não reduziria sua nota, mesmo que seu desempenho tivesse caído.

Na literatura, o que se vê, é que os professores universitários, de maneira geral, mesmo os que possuem títulos (mestres e doutores), têm dado pouca importância a sua preparação didático-pedagógica para a docência. É sabido, segundo os autores, 
que o critério para seleção e contratação destes professores tem sido a marca de um bom desempenho profissional na sua especialidade, não necessariamente com domínio na área educacional e pedagógica ${ }^{14}$.

Correlacionando-se os dados de tempo de magistério no ensino superior com a afirmativa: "Sempre utilizo a planilha com os critérios para avaliação formativa em tutorias", a maioria (78\%) optou pela opção sim, sempre usava, independentemente do tempo de magistério, mas chamou atenção que mesmos os tutores mais experientes (três em quatro) com tempo de quinze anos ou mais, e 12 (de 14) com tempo entre seis a dez anos, mesmo mais experientes, continuaram usando a planilha de avaliação.

O único professor que assinalou que não utilizava a planilha pertencia ao grupo de menor experiência (de até cinco anos). No trabalho de Rozendo ${ }^{14}$ foi identificado que a maior parte dos professores tinha no máximo cinco anos de experiência no ensino superior e sem preparação específica para a docência.

Quanto a correlação do tempo de experiência em metodologias ativas com a assertiva: "Sempre utilizo a planilha com os critérios para avaliação formativa em tutorias", evidenciou-se que a maioria dos tutores (21 de 27) sempre usava a planilha, independente do tempo de experiência, sendo sete (de oito) com tempo de experiência de seis ou mais anos; nove (de 12) com tempo de experiência entre três a cinco anos; e cinco (de sete) com tempo de experiência até dois anos. Dentre os 27 docentes, apenas um docente não usava a planilha de avaliação, pertencendo ao grupo com menor experiência em metodologias ativas (de até dois anos), sugerindo talvez que os docentes com menor tempo de experiência em ensino superior e também em metodologias ativas deveriam ser submetidos a uma melhor qualificação. Embora cursos de didática não sejam suficientes para tornar um docente com habilidades necessárias para o ensino, esses são recursos importantes para sua preparação e melhor desempenho ${ }^{14}$.

\section{Conclusão}

Apesar do estudo confirmar que a maioria dos docentes possuía experiência no ensino superior, ficou clara também a pouca vivência com metodologias ativas.

Para que haja então a facilitação na aplicação destas metodologias e, sobretudo, no processo de avaliação dos alunos, sugere-se a realização de mudanças, tanto na descrição, como nas pontuações dos critérios da planilha de avaliação formativa.

Ter uma planilha formativa bem articulada ao processo de avaliação é essencial, pois observou-se que mesmo os professores mais experientes continuavam a utilizar a planilha de avaliação e, independente do tempo de ensino superior, foi senso comum a solicitação de mudanças nos critérios de avaliação, o que afasta a hipótese de que apenas os professores com pouca experiência poderiam não saber utilizar a planilha corretamente.

O estudo reflete, ainda, que se tenha mais atenção com estes professores com menor experiência em ensino superior e em metodologias ativas, devendo os processos tutoriais e as dinâmicas de grupo serem revistas regularmente por todos os tutores, uma vez que foram observadas várias discordâncias entre os docentes com relação a posição adotada à mesa, arredondamento de notas, subtração de pontos e erros de português.

As principais dificuldades observadas como motivar turmas desinteressadas, estimular o aluno tímido que sobrecarrega os colegas e avaliar turmas grandes, poderiam ser minimizadas com acesso a programas de qualificação continuada.

Além disso, não houve correlação entre a alta titulação docente e a rotulação de alunos, diferentemente do que se poderia supor. Mas entre os professores especialistas, observou-se a rotulação do aluno de baixo rendimento, sugerindo que estes professores necessitariam ter maior experiência na área educacional e pedagógica. 
Apesar disso, fica claro que a participação dos sujeitos (tutores) desse estudo é de uma realidade específica (lócus de pesquisa), mas que se assemelham a tantas outras realidades educativas (locais, regionais, nacionais, internacionais) que optaram em construir uma formação acadêmica - educação médica - pelo viés de um currículo PBL.

Portanto, para ajudar na avaliação formativa, faz-se necessária mudanças de acordo com os resultados obtidos em pesquisas individualizadas. Caso se percebam fragilidades, estas devem, se possível, ser corrigidas, pois mostram onde estão as dificuldades a serem trabalhadas.

Afinal, pensar em processos avaliativos não é tarefa das mais fáceis para uma instituição e para os profissionais que dela fazem parte. É uma tarefa que requer disciplina teórica para apreender conhecimentos que elucidem soluções para as dificuldades encontradas pelos sujeitos e o desejo de sempre estarem receptivos para melhorias e evoluções necessárias.

\section{Referências}

1. Brasil. Conselho Nacional de Educação. Câmara de Educação Superior. Resolução CNE/CES n. 4, de 7 de novembro de 2001. Institui Diretrizes Curriculares Nacionais do Curso de Graduação em Medicina. Diário Oficial da União, Brasília, DF, 2001, Seção 1, p. 38.

2. Gomes R, Brino RF, Aquilante AG, Avó LRS. Aprendizagem Baseada em Problemas na formação médica e o currículo tradicional de Medicina: uma revisão bibliográfica. Rev Bras Educ Med. 2009;33(3):433-40. http://dx.doi.org/10.1590/ S0100-55022009000300014.

3. Toledo Júnior ACC, Ibiapina CC, Lopes SCF, Rodrigues ACP, Soares SMS. Problems-based learning: a new reference for constructing the medical curriculum. Rev. Méd. de Minas Gerais. 2008;18(2):123-31. http://rmmg.org/artigo/detalhes/521

4. Perrenoud $P$, Zeichner KM, organizadores. A pesquisa na formação e no trabalho docente. Belo Horizonte: Autêntica; 2002.

5. Suhr IRF. Processo avaliativo no ensino superior. Curitiba (PR): IBPEX; 2008.

6. Cunha MI. Docência na universidade, cultura e avaliação institucional: saberes silenciados em questão. Rev Bras Educ. 2006;11(32):258-71. http://dx.doi.org/10.1590/S1413-24782006000200005.

7. Troncon LEA. Avaliação do estudante de medicina. Medicina, Ribeirão Preto. 1996;29(4):429-39.

8. Freire P. Pedagogia da autonomia: saberes necessários à prática educativa. Rio de Janeiro: Paz e Terra; 1999.

9. Fernandes D. Para uma teoria da avaliação formativa. Rev Port Educ. 2006;19(2):21-50.

10. Veiga IPA, Naves ML. Currículo e avaliação na educação superior. In: Mendes, OM. Avaliação formativa no ensino superior: reflexões e alternativas possíveis. São Paulo (SP): Junqueira \& Marin; 2005. p. 175-197.

11. Horta FMB. A sessão tutorial na ABP do curso médico da Unimontes: desafios e possibilidades. [dissertação]. São Paulo (SP): Universidade Federal de São Paulo; 2010.

12. Bellodi PL, Martins MA. Tutoria: Mentoring na formação médica. São Paulo (SP): Casa do Psicólogo; 2005 . p. 79-80.

13. Hendry GD, Ryan G, Harris J. Group problems in problem-based learning. Med Teach. 2003;25(6):609-16. http://dx.doi.or g/10.1080/0142159031000137427. PMid:15369908.

14. Rozendo CA, Casagrande LDR, Schneider JF, Pardini LC. Uma análise das práticas docentes de professores universitários da área de saúde. Rev Latino-Am Enfermagem. 1999;7(2):15-23. http://dx.doi.org/10.1590/S0104-11691999000200003.

\section{Contribuição dos autores}

Marilia de Fátima Silva Pinheiro participou desde a concepção e desenvolvimento de todo o artigo, coletou e fez o levantamento da literatura utilizada, realizou a redação e revisão crítica. Milena Coelho Fernandes Caldato participou desde a concepção, desenho metodológico e desenvolvimento de todo o artigo, fez a supervisão, redação e revisão crítica. Jackson Cordeiro Lima realizou a análise estatística, avaliação e apresentação dos resultados e revisão crítica. Fabíola de Carvalho Chaves de Siqueira Mendes realizou a redação, análise estatística, avaliação e apresentação dos resultados e revisão crítica. 